\title{
Healthcare professionals have a vital role to play in safeguarding older people from abuse
}

\section{Caroline Abrahams Age UK's charity director}

Substantial numbers of older people experience financial, emotional, and physical abuse. Those with dementia and other health and care needs can be particularly at risk. It's surely equally obvious that older people can be both victims, and perpetrators, of domestic abuse, just like anyone else. Yet this is not something that's talked about much-perhaps because older people have been largely absent from the official statistics on domestic abuse, since the data collection organised by the Office for National Statistics (ONS) in the ONS Crime Survey of England and Wales (CSEW) stops at age 74. At Age UK we thought this a flagrant example of ageism so we campaigned to change it. We were delighted when the ONS agreed earlier this year to remove this age limit from now on, because it should help us gain a better understanding of the nature and prevalence of domestic abuse among older people in this country. ${ }^{1}$ It should also shed some light on levels of domestic abuse in older adults-a hidden and rarely talked about issue-and stimulate new forms of support.

However, until this new approach beds in we have to rely on what older people tell us. During the past 18 months, for example, Age UK's advice line has received more than two queries a day about domestic abuse. It's clear that the pandemic has made life much harder for people living with domestic abuse, since it's a crime that thrives behind closed doors and there were a lot of them these last 18 months or so, particularly during lockdowns. The pandemic also meant that for someone who is normally able to leave home to get away from the abuse for a while (recognising that some never can), this became far more difficult. Sadly, some domestic abuse victims had to decide which they feared the most: the reality of abuse at home, or the risk of contracting the virus if they went out and about.

Age impacts all of us in different ways: An older woman told us she finally got some relief from her partner's violence, after many years of living with it, because he was no longer physically capable of hurting her. However, we also hear from people who begin to experience domestic abuse for the first time in later life, perhaps linked to the perpetrator's physical or mental health problems. And of course, domestic abuse does not only occur between older partners, but between older people and their adult children, and others close to them too.

What's this got to do with health professionals and their teams? A lot in our view. Staff who work with older people are well placed to spot situations in which an older person may be at risk of or experiencing abuse. Primary care professionals have the most obvious part in this, but they are not the only ones. Antennae should also begin to twitch, for example, if an older person who has been admitted to hospital seems extremely reluctant to go home, for no very obvious reason. Or indeed if their family or partner seem unduly anxious about the prospect. Community health professionals should note if they enter an older person's home and feel that something isn't quite right with their behaviour, or the interaction they see between them and someone else living there gives cause for concern.

There are however barriers in the way of health professionals being able to play this vital safeguarding role. One is time: if everyone is rushed and focused mainly on performing the task at hand it is less likely they will pick up these signs, even if an older person is trying to communicate their distress in an effort to be heard. But perhaps the bigger barrier is attitudinal: for many health professionals, like the rest of us, the thought of older people being subjected to, or perpetrating, abuse is somewhere on the spectrum between highly unfamiliar and downright shocking. It is not what we have been taught to expect in a society which often seems to bracket older people as “other." Yet when it comes to domestic abuse, and in fact to abuse in all its forms, unfortunately they are anything but "other."

Uncomfortable as it may be, we need to accept that abuse impacts on some older people and make this part of the policy and practice discourse. Just like everyone else, older people experiencing abuse need support now and follow-up care once they are no longer in an abusive situation too. The safeguarding training and awareness raising that health professionals receive must now not only include identifying domestic abuse alongside other forms of abuse, but how this is experienced by older people, and how to deal with concerns. By breaking the taboo we'll be doing an important service to all those affected and making it more likely that they will be able to get the help they need.

\section{Competing interests: none declared}

Provenance and peer review: commissioned, not peer reviewed

No age limit: older people and domestic abuse https://www.ageuk.org.uk/our-impact/campaigning/no-age-limit/ 